15

\title{
Фоторезистор инфракрасного излучения на основе кремния с нанокластерами атомов марганца
}

\author{
(С) М.К. Бахадирханов, Ш.Н. Ибодуллаев , Н.Ф. Зикриллаев, С.В. Ковешников \\ Ташкентский государственный технический университет, Ташкент, Узбекистан \\ ฯ E-mail: shakhboz.ibodullayev.92@inbox.ru
}

Поступило в Редакцию 13 октября 2020 г.

В окончательной редакции 30 марта 2021 г.

Принято к публикации 1 апреля 2021 г.

\begin{abstract}
Показана возможность использования кремния с нанокластерами атомов марганца для создания фоторезисторов в области спектра $\lambda=1.2-3 \mu \mathrm{m}$. Установлено, что такие фотоприемники обладают пороговой чувствительностью порядка $10^{-11} \mathrm{~W}$ на длине волны $1.55 \mu \mathrm{m}$. Квантовая эффективность на длине волны $2 \mu \mathrm{m}$ превышает $10 \%$ и составляет $0.1 \%$ на длине волны $2.5 \mu \mathrm{m}$, что позволяет использовать примесную фоточувствительность кремния с нанокластерами атомов марганца для создания высокоразрешающих матричных фотоприемников, работающих в спектральном диапазоне до $2.5 \mu \mathrm{m}$.
\end{abstract}

Ключевые слова: кремний, кластер марганца, фоточувствительность.

DOI: 10.21883/PJTF.2021.13.51114.18582

\begin{abstract}
Фотоприемники ИК-излучения диапазона $\lambda=10-2.5 \mu \mathrm{m} \quad$ востребованы преимущественно в качестве матричных телевизионных устройств для создания тепловизоров [1]. В матрицах,
\end{abstract} работающих на собственном внутреннем фотоэффекте, применяются такие материалы, как $\mathrm{PbS}, \mathrm{PbSe}, \mathrm{InSb}$, $\mathrm{Ga}_{x} \mathrm{In}_{1-x} \mathrm{As}_{y} \mathrm{Bi}_{z} \mathrm{Sb}_{1-y-z} / \mathrm{InSb},(\mathrm{CdHg}) \mathrm{Te}$ и др. [1-4]. Однако создание высокоразрешающих матриц непосредственно на основе этих материалов практически невозможно, так как требуется их стыковка с кремниевыми усилительными и управляющими элементами. В то же время возможности кремния для создания фотоприемников на основе примесного фотоэффекта далеко не исчерпаны.

В этом плане представляет интерес кремний с нанокластерами атомов марганца. Как показано в работе [5], при определенных соотношениях концентрации нанокластеров $N_{c}$ и концентрации носителей заряда $p$-типа $\left(N_{c} \gg p\right)$ могут образовываться примесные минизоны, которые могут привести к существенному расширению спектральной области чувствительности кремниевой матрицы.

В связи с этим цель настоящей работы состоит в том, чтобы показать возможность создания фотоприемников на основе кремния с нанокластерами атомов марганца, пригодных для получения высокоразрешающих монолитных матричных фотоприемников, и определить их основные параметры.

В качестве исходного материала использовался монокристаллический кремний $p$-типа, легированный бором, с удельным сопротивлением $\rho=3 \Omega \cdot \mathrm{cm}$ (концентрация дырок $\left.p=7 \cdot 10^{15} \mathrm{~cm}^{-3}\right)$. Легирование марганцем проводилось методом „низкотемпературной“ диффузии [6]. Условия диффузии подбирались таким образом, чтобы получить практически полностью компенсированный кремний $p$-типа с удельным сопротивле- нием $\rho=5 \cdot 10^{3}-5.8 \cdot 10^{4} \Omega \cdot \mathrm{cm}$. В таких образцах атомы марганца находятся преимущественно в двукратно ионизованном виде $\left(\mathrm{Mn}^{++}\right)$. Кроме того, согласно [7], обеспечиваются высокое зарядовое состояние кластеров, имеющих структуру типа $\mathrm{Mn}_{4} \mathrm{~B}$, и условие образования минизон.

Электрические параметры образцов были исследованы методом эффекта Холла. Для исследования спектральной зависимости фотопроводимости использовался монохроматор на основе установки ИКС-21, снабженной криостатом (температура образцов в процессе измерений находилась в диапазоне 95-105 K). Чтобы исключить попадание рассеянного в монохроматоре, а также фонового излучения на образец, использованы фильтры из двусторонне полированных кремниевых пластин толщиной $d \sim 380 \mu \mathrm{m}$, которые устанавливались на входе монохроматора и непосредственно в окошке криостата. Мощность падающего на образец излучения в этих измерениях поддерживалась постоянной и составляла $6.5 \cdot 10^{-6} \mathrm{~W}$.

На рис. 1, $a$ показана типичная спектральная зависимость фототока образцов кремния с нанокластерами атомов марганца, измеренная в области „примесной“ фотопроводимости при наличии электрического поля в образце $6.5 \mathrm{~V} / \mathrm{cm}$.

Как видно из рисунка, фотоответ в таких образцах начинается при $h v=0.16 \mathrm{eV}(\lambda=8 \mu \mathrm{m})$. При этом наблюдается три области спектральной чувствительности, которые существенно отличаются друг от друга. Первая область $-h v=0.16-0.4 \mathrm{eV}$, значение фототока монотонно увеличивается в указанной области спектра почти на два порядка. Вторая область - $h v=0.4-0.6 \mathrm{eV}$ $(\lambda=3.1-2.06 \mu \mathrm{m})$, в этом диапазоне значение фототока увеличивается почти на 5.5 порядка, т.е. имеет место аномально большое изменение фототока (в ин- 

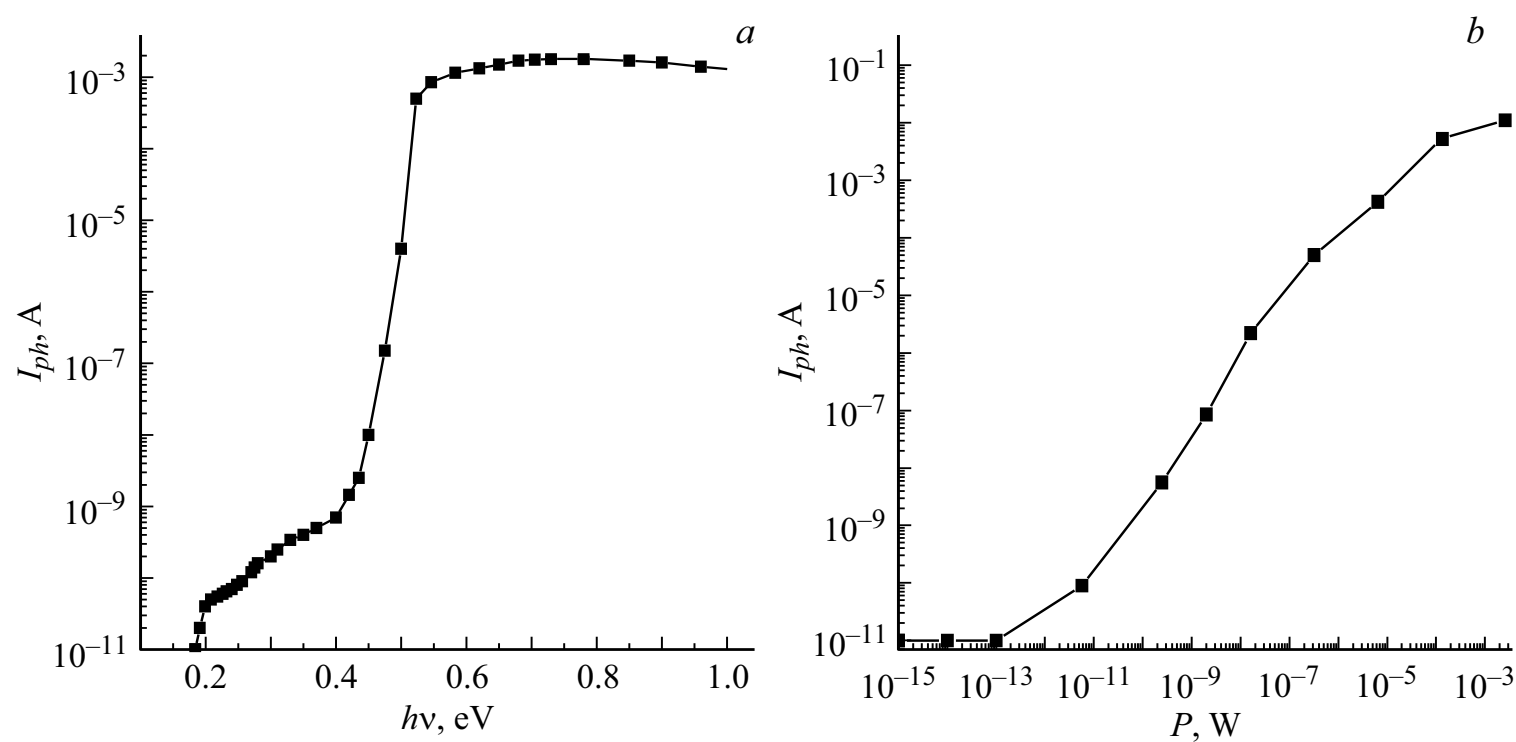

Рис. 1. Характеристики фоторезистора. $a-$ типичная спектральная зависимость фототока фоторезистора; $b-$ зависимость фототока от мощности падающего излучения при энергии квантов $h v=0.78 \mathrm{eV}$.

тервале всего $\Delta h v=0.2 \mathrm{eV})$. В третьей области $h v=0.6-1 \mathrm{eV}(\lambda=2.06-1.2 \mu \mathrm{m})-$ фототок сохраняет аномально большое значение $\left(\sim 10^{-3} \mathrm{~A}\right)$ и практически не зависит от энергии фотона.

Такие спектральные зависимости фоточувствительности имеют образцы с удельным сопротивлением $\rho=5 \cdot 10^{3}-2 \cdot 10^{4} \Omega \cdot \mathrm{cm}$ (при $T=300 \mathrm{~K}$ ), а самая высокая фоточувствительность наблюдается в образцах с удельным сопротивлением $\rho=(5-8) \cdot 10^{3} \Omega \cdot \mathrm{cm}$. Это означает, что на основе кремния с нанокластерами атомов марганца можно получить резистивные фотоприемники, работающие в широком интервале ИК-спектра (до $\lambda=8 \mu \mathrm{m}$ ).

На основе исследованных образцов с $\rho=(5-8) \cdot 10^{3} \Omega \cdot \mathrm{cm}$ были разработаны и изготовлены фотоприемники с никелевыми химически осажденными контактами и фоточувствительной площадью $4 \times 2 \mathrm{~mm}$, далее приводится методика измерения их основных параметров.

Для исследования пороговой чувствительности фотоприемника интенсивность падающего света изменялась с помощью кремниевых фильтров, работающих как ослабители излучения. Ослабление излучения происходит как за счет диэлектрического отражения от передней и задней поверхностей, так и за счет поглощения. Использовалось до 10 штук двусторонне полированных кремниевых пластин с толщиной $d \sim 380 \mu \mathrm{m}$, которые устанавливались последовательно (с расстоянием между фильтрами $2 \mathrm{~mm}$ ) перед монохроматором спектрометра ИКС-21. Фильтры располагались в корпусе, полностью устраняющем возможное фоновое освещение фильтров, которое может привести к изменению их пропускания.

Интенсивность падающего ИК-излучения без фильтров определялась измерителем мощности ИМО-2Н.
С помощью отдельных измерений показано, что каждый фильтр уменьшает мощность излучения в 20 раз. Таким образом, использование до 10 фильтров последовательно позволило нам изменять мощность излучения в интервале $P=10^{-13}-10^{-3} \mathrm{~W}$. Зависимость фототока фоторезистора от мощности падающего излучения $(h v=0.78 \mathrm{eV})$ показана на рис. $1, b$.

Как видно из рисунка, в интервале мощности падающего излучения $P=10^{-11}-10^{-4} \mathrm{~W}$ зависимость фототока фоторезистора соответствует теоретической (линейной) зависимости от мощности, а отклонения, наблюдающиеся при $P>10^{-4} \mathrm{~W}$, могут быть связаны с изменением пропускания первого фильтра за счет фонового освещения и излучения глобара. Поскольку мощность монохроматического излучения пропорциональна количеству квантов света в единицу времени (через энергию фотонов), а фототок также пропорционален количеству квантов света в единицу времени (через квантовый выход), между фототоком и мощностью монохроматического излучения должна наблюдаться линейная зависимость.

Пороговая чувствительность была оценена по графику (рис. $1, b)$ путем сравнения темнового тока прибора (что по порядку величины соответствует уровню шума) с экстраполированной величиной фототока. Установлено, что разработанный фоторезистор на основе $\mathrm{Si}$ c нанокластерами имеет пороговую чувствительность по мощности порядка $P \sim 10^{-11} \mathrm{~W}$ (при $T=100 \mathrm{~K}$ ) на длине волны $1.55 \mu \mathrm{m}$, что лучше, чем для кремниевых фотоприемников, полученных с помощью других технологий [8] на этой длине волны ИК-излучения.

Исследовалась спектральная зависимость токовой чувствительности разработанного фотоприемника. На рис. 2, a показана спектральная зависимость то- 

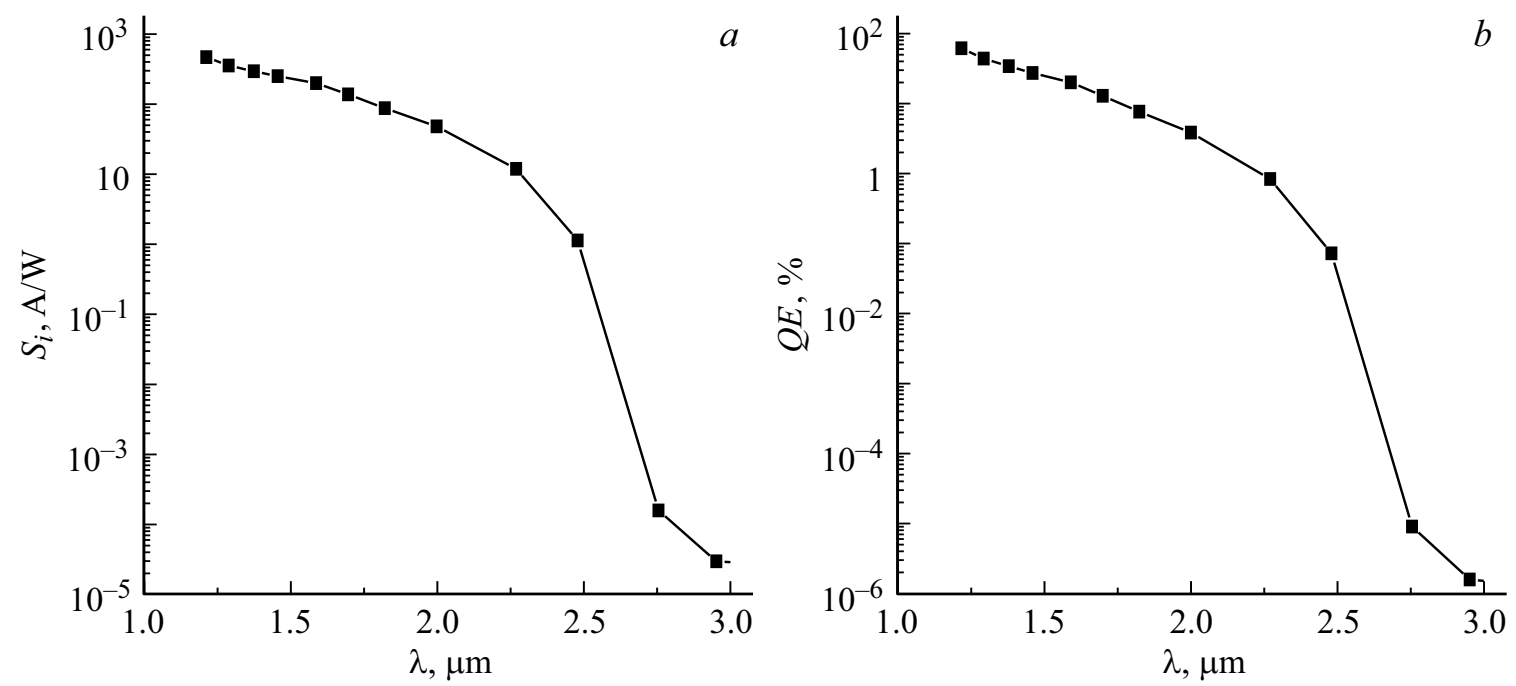

Рис. 2. Спектральные зависимости фоторезистора. $a-$ зависимость токовой чувствительности, $b-$ зависимость квантового выхода.

ковой чувствительности фотоприемника в области $\lambda=1.2-3 \mu \mathrm{m}$ при напряженности электрического поля $\sim 6.25 \mathrm{~V} / \mathrm{cm}$. Для длины волны $1.2-1.6 \mu \mathrm{m}$ токовая чувствительность достигает $S \sim 500-100 \mathrm{~A} / \mathrm{W}$, в интервале $\lambda=1.6-2.3 \mu \mathrm{m}$ она уменьшается от 100 до $10 \mathrm{~A} / \mathrm{W}$, далее на длине волны $2.5 \mu \mathrm{m}$ токовая чувствительность спадает до $S=1.15 \mathrm{~A} / \mathrm{W}$, оставаясь достаточно высокой для практического применения, а затем быстро уменьшается с ростом длины волны ИК-излучения.

Токовая чувствительность данного фотоприемника, достигающая сотен $\mathrm{A} / \mathrm{W}$ в области спектра $1.2-1.6 \mu \mathrm{m}$, превосходит фоточувствительность инфракрасных фотодиодов (токовая чувствительность для $p-i-n$-фотодиодов в рабочем диапазоне длин волн составляет $0.5-0.8 \mathrm{~A} / \mathrm{W}$, а для лавинных фотодиодов достигает 20-60 A/W [9]).

Квантовая эффективность является одним из основных параметров фотоприемника. Квантовая эффективность $(Q E)$ - физическая величина, равная отношению числа носителей заряда $\left(N_{p}\right)$, образованных при освещении образца, к общему числу поглощенных фотонов $\left(N_{p h}\right)$.

Поскольку точное значение коэффициента усиления фоторезистора неизвестно, квантовый выход вычислялся относительно квантового выхода собственного фотоэффекта с использованием токовой чувствительности. На рис. 2, $b$ представлена расчетная зависимость $Q E$ фотоприемника от длины волны падающих фотонов. Квантовый выход в области собственного поглощения считался равным $85 \%$.

Как видно из рис. 2, $b$, разработанный фоторезистор на основе кремния с нанокластерами атомов марганца обеспечивает квантовую эффективность $Q E$ порядка $10 \%$ до длины волны $2 \mu \mathrm{m}$ и около $0.1 \%$ на длине волны $2.5 \mu \mathrm{m}$. Это позволяет использовать примесную чувствительность кремния с нанокластерами атомов марганца для создания высокоразрешающих матричных фотоприемников на основе кремния в диапазоне до $2.5 \mu \mathrm{m}$.

Для оценки быстродействия фотоприемника исследовался временной отклик тока фоторезистора на импульсную модуляцию света. Для измерения тока использовалась низкоомная $(100 \Omega)$ нагрузка. В качестве модулятора использовался вращающийся с частотой $3000 \mathrm{rpm}$ металлический диск диаметром $150 \mathrm{~mm}$ со щелями шириной $1 \mathrm{~mm}$ по его краю, установленный вплотную к входной щели монохроматора. При ширине щели монохроматора $1 \mathrm{~mm}$ импульсы света имеют треугольную форму и обладают длительностью на полувысоте около $80 \mu \mathrm{s}$. Быстродействие фотоприемников в области спектра $\lambda=1.7-3 \mu \mathrm{m}$, оцененное по двухлучевой осциллограмме импульсов тока, имеет порядок единиц микросекунд. Оценивался сдвиг фазы импульсов тока фоторезистора относительно опорных импульсов тока, генерируемых фотодиодом ФД-256 с обратным смещением $10 \mathrm{~V}$ на нагрузке сопротивлением $100 \Omega$. Освещение фотодиода производилось лазером красного света. В области $\lambda=1.2-1.7 \mu \mathrm{m}$ быстродействие определялось по длительности затухания фотопроводимости (т.е. по спаду импульса тока фоторезистора в $e$ раз) и составляло сотни миллисекунд. Причины столь существенного различия быстродействия в зависимости от спектрального диапазона излучения не совсем ясны, и требуются дополнительные исследования.

Таким образом, установлено, что кремний с нанокластерами Мn позволяет создавать высокочувствительные примесные фоторезисторы в ИК-области спектра с параметрами не хуже, чем у существующих ИК-фотоприемников типа $p-i-n$ и лавинных диодов на основе твердых растворов $\mathrm{A}^{3} \mathrm{~B}^{5}$. Особо следует подчеркнуть, что технология таких фотоприемников совместима с технологией кремниевых интегральных схем, и соответственно они могут использоваться при создании охлаждаемых вы- 
сокоразрешающих монолитных матричных приемников ближнего ИК-диапазона.

\section{Конфликт интересов}

Авторы заявляют, что у них нет конфликта интересов.

\section{Список литературы}

[1] М.А. Тришенков, И.И. Таубкин, А.М. Филачев, Электронная техника. Сер. 2. Полупроводниковые приборы, № 1 (224), 31 (2010).

[2] Е. Певцев, В. Чернокнижин, Электронные компоненты, № 1-3, 12 (2001).

[3] В.И. Стафеев, К.О. Болтарь, ФТП, 39 (10), 1257 (2005).

[4] В. Волков, Электронные компоненты, № 1, 1 (2008).

[5] М.К. Бахадырханов, К.С. Аюпов, Г.Х. Мавлянов, Х.М. Илиев, С.Б. Исамов, Микроэлектроника, 39 (6), $426(2010)$

[6] Б.А. Абдурахманов, К.С. Аюпов, М.К. Бахадырханов, Х.М. Илиев, Н.Ф. Зикриллаев, 3.М. Сапарниязова, Доклады АН Республики Узбекистан, № 4, 32 (2010).

[7] М.К. Бахадырханов, Г.Х. Мавлонов, С.Б. Исамов, Х.М. Илиев, К.С. Аюпов, 3.М. Сапарниязова, С.А. Тачилин, Неорган. материалы, 47 (5), 545 (2011).

[8] А.К. Будтолаев, А.К. Будтолаева, Н.В. Кравченко, П.Е. Хакуашев, И.В. Чинарёва, М.А. Тришенков, Успехи прикл. физики, 6 (6), 494 (2018).

[9] М.Л. Бараночников, Приемники и детекторы излучений: справочник (ДМК Пресс, М., 2012). 